\title{
Planning Rehabilitation and Allied Health Professional Input for Older Inpatients During the COVID-19 Pandemic
}

\author{
Shyh Poh Teo (iD) ${ }^{1}{ }^{*}$ \\ ${ }^{1}$ Department of Internal Medicine, RIPAS Hospital, Bandar Seri Begawan, Brunei Darussalam, Brunei \\ "Corresponding author: Consultant Geriatrician and Physician, Department of Internal Medicine, RIPAS Hospital, Jalan Putera Al-Muhtadee Billah, Bandar Seri Begawan, \\ BA1710, Brunei Darussalam, Brunei. Email: shyhpoh.teo@moh.gov.bn
}

Received 2020 June 22; Revised 2020 August 17; Accepted 2020 August 18.

Keywords: Aged, Allied Health Personnel, Rehabilitation, SARS-CoV

\section{Dear Editor,}

This letter describes a suggested approach for planning rehabilitation and allied health professional input for older inpatients during the COVID-19 pandemic. The coronavirus disease 2019 (COVID-19) is caused by the 'Severe acute respiratory syndrome coronavirus 2' (SARS-CoV-2) virus. It is highly infectious through respiratory secretions and remains viable for some time on contact surfaces (1). This novel virus has led to an international pandemic and affected healthcare services globally. Services had to be reorganized, an initial rush to provide acute care for COVID19 patients, followed by a domino effect on other services due to acute staff requirements in the front-line and the need for pro-active planning to take into account measures to reduce viral transmission, including social distancing.

For older people, including those not infected by SARSCOV-2, this impact on medical services has significant implications, particularly those who require comprehensive geriatric assessment and multidisciplinary intervention to improve functional outcomes. A study of Geriatric Medicine inpatients in our local hospital identified a high demand for allied health professional input with $60 \%$ of inpatients referred for physiotherapy, $25 \%$ occupational therapy, $60 \%$ dietetics, and 30\% speech-language therapy, which was also reflected in the distribution of bed days, where the rehabilitation and discharge planning took $38 \%$ of their hospital stay (2).

Locally, positive SARS-COV-2 patients are treated in the National Isolation Centre, where strict infection control guidelines, including wearing full personal protective equipment(PPE), are mandatory for the staff. Patients with possible acute COVID-19 infections are managed in isolation wards, while SARS-COV-2 test results are pending. Clinicians still refer medical inpatients for rehabilitation and allied health professional input, even if they are nursed in isolation wards.

Rehabilitation is necessary for COVID-19 patients to restore motor function and promote psychological recovery. The rehabilitation programs may be categorized as follows: aerobic exercise, strength training, static and dynamic balance training, bronchial clearance, evaluation of activities of daily living, and neuropsychological training (3). Critically unwell patients on admission may encounter prolonged immobility and musculoskeletal deconditioning and require intense rehabilitation. For individual patients, clinicians need to balance the risk versus benefit between delayed rehabilitation and associated poor functional outcomes with the risk of exposing healthcare professionals to potentially-infectious patients.

General recommendations for all older patients to reduce the risk of deconditioning should be emphasized by all clinical staff, including maintaining mobility, avoiding physical inactivity, and malnutrition screening. Considerations should be given for history taking, goal-setting, and discussions by tele or video-conferencing facilities if possible. An adapted approach to minimize patient contact for referrals to allied health professionals is summarized in Table 1. Essentially, most indications are non-urgent and can be remotely done or deferred until the person is no longer infectious. The main exception (to remote review or deferred physiotherapy input) is chest physiotherapy to assist sputum clearance, or in high-risk patients such as cystic fibrosis (4).

For patients with dysphagia, clinical, and endoscopic swallow assessments are not recommended due to the high risk of spreading contagion through projections of droplets when coughing. If oral feeding is unsafe, alternative nutrition approaches should be considered after dis- 


\begin{tabular}{|c|c|c|}
\hline Allied Health Professional & Indication & Adaptation of Approach \\
\hline \multirow{2}{*}{ Physiotherapy } & Mobility & $\begin{array}{l}\text { For all patients, stay active advice, initial assessment (PPE required) prescribe } \\
\text { patient exercises. Limited follow-up to reduce exposure. }\end{array}$ \\
\hline & Chest & $\begin{array}{l}\text { Negative pressure side-room, Precautions for aerosol-generating procedures, } \\
\text { Limit nebulizer use. }\end{array}$ \\
\hline \multirow{3}{*}{ Occupational Therapy } & Environmental assessment & $\begin{array}{l}\text { Take a history of barriers and hazards to plan required home modifications, } \\
\text { defer home evaluation to pre-discharge, check if household members have ILI } \\
\text { symptoms or under quarantine orders. }\end{array}$ \\
\hline & Functional assessment & $\begin{array}{l}\text { Initial assessment (PPE required) and plan routine or schedule, defer } \\
\text { evaluation to pre-discharge, Liaison with nursing staff and other allied health } \\
\text { professionals regarding participation in activities of daily living. }\end{array}$ \\
\hline & Equipment & $\begin{array}{l}\text { Defer evaluation to pre-discharge after the confirmation of the functional } \\
\text { status. }\end{array}$ \\
\hline Medical Social Worker & $\begin{array}{l}\text { Social/financial assessments complex family } \\
\text { discussions }\end{array}$ & $\begin{array}{l}\text { Defer evaluation to pre-discharge, telephone or video conference to contact } \\
\text { patient and family members, Minimize face-to-face meetings or discussions. }\end{array}$ \\
\hline \multirow{3}{*}{ Dietetics } & Enteral feeding & $\begin{array}{l}\text { Nursing staff to weigh patient and monitor tolerance to enteral feeds, dietitian } \\
\text { to calculate caloric requirements and prescribe feeds }\end{array}$ \\
\hline & Malnutrition & $\begin{array}{l}\text { Clinical and nursing staff to screen and refer as indicated, Food charts and } \\
\text { weight chart reviews. }\end{array}$ \\
\hline & Diabetes & $\begin{array}{l}\text { Diabetes dietary information sheets to be provided by the patient, Phone-call } \\
\text { follow-up. }\end{array}$ \\
\hline \multirow{2}{*}{$\begin{array}{l}\text { Speech and Language } \\
\text { Therapy (SLT) }\end{array}$} & Swallow assessment & $\begin{array}{l}\text { Initial assessment (PPE required), clinical and nursing staff to perform } \\
\text { screening bedside swallow assessment, then monitor for signs of aspiration } \\
\text { after SLT recommendations. }\end{array}$ \\
\hline & Speech rehabilitation & $\begin{array}{l}\text { Initial assessment (PPE required), prescribe patient exercises, limited follow-up } \\
\text { to reduce exposure. }\end{array}$ \\
\hline
\end{tabular}

Abbreviations: PPE, personal protective equipment; ILI, influenza-like illness

cussion with the multidisciplinary team (5). Each patient encounter is an opportunity to be maximized. For example, a physiotherapist reviewing mobility may enquire regarding environmental barriers at home and provide exercises for patients before the next review. Patients should also be prescribed exercises with the expectation that they eventually develop self-efficacy in the progression of therapy. This may be facilitated by providing a printed exercise program for patients with pre-planned advice on increasing repetitions or weights.

In conclusion, it is possible to provide rehabilitation during the COVID-19 pandemic with foresight and planning for this 'new normal'. While the pandemic necessitates limiting social contact to reduce infection and transmission risk, proactive planning should ameliorate the impact of these restrictions on rehabilitation services and outcomes.

\section{Footnotes}

Authors' Contribution: SPT was involved in a study concept and design, acquisition of data, analysis, and interpretation of data, and drafting and finalizing the manuscript for important intellectual content.
Conflict of Interests: No conflicts of interest declared. Funding/Support: No funds were obtained for the production of this manuscript.

\section{References}

1. Del Rio C, Malani PN. 2019 Novel Coronavirus-Important Information for Clinicians. JAMA. 2020;323(11):1039-40. doi: 10.1001/jama.2020.1490. [PubMed: 32022836].

2. Teo SP. Geriatrics inpatients in RIPAS Hospital, Brunei: Patient characteristics and rehabilitation needs. J Clin Gerontol Geriatr. 2018;9(2):529. doi: 10.24816/jcgg.2018.v9i2.04.

3. Brugliera L, Spina A, Castellazzi P, Cimino P, Tettamanti A, Houdayer E, et al. Rehabilitation of COVID-19 patients. J Rehabil Med. 2020;52(4):jrm00046. doi: 10.2340/16501977-2678. [PubMed: 32286674].

4. Thomas P, Baldwin C, Bissett B, Boden I, Gosselink R, Granger CL, et al. Physiotherapy management for COVID-19 in the acute hospital setting: clinical practice recommendations. J Physiother. 2020;66(2):7382. doi: 10.1016/j.jphys.2020.03.011. [PubMed:32312646]. [PubMed Central: PMC7165238].

5. Mattei A, Amy de la Breteque B, Crestani S, Crevier-Buchman L, Galant C, Hans S, et al. Guidelines of clinical practice for the management of swallowing disorders and recent dysphonia in the context of the COVID-19 pandemic. Eur Ann Otorhinolaryngol Head Neck Dis. 2020;137(3):173-5. doi: 10.1016/j.anorl.2020.04.011. [PubMed: 32332004]. [PubMed Central: PMC7167576]. 